\title{
Extrauterine myxoid leiomyoma mimicking an aggressive angiomyxoma
}

\author{
Sze-Ryn Chung ${ }^{1}$, Tiffany Priyanthi Hennedige ${ }^{2}$, Kesavan Sittampalam $^{3}$, Melissa Ching Ching Teo ${ }^{1}$ \\ 1. Department of Surgical Oncology, National Cancer Centre Singapore, Singapore. 2. Department of Oncologic Imaging, \\ National Cancer Centre Singapore, Singapore 3. Department of Pathology, Singapore General Hospital, Singapore.
}

Correspondence: Sze-Ryn Chung. Address: Department of Surgical Oncology, National Cancer Centre Singapore, Singapore. E-mail: szeryn@gmail.com

Received: October 26, 2014

Accepted: December 15, 2014

Online Published: December 22, 2014

DOI : $10.5430 /$ crcp.v2n2p51

URL: http://dx.doi.org/10.5430/crcp.v2n2p51

\section{Abstract}

Introduction: Leiomyomas are benign smooth muscle tumours that usually arise from the uterus. Extrauterine leiomyomas are rare. We present a case of an extrauterine myxoid leiomyoma in a perimenopausal woman.

Case: A 47-year-old woman presented with an increase in abdominal girth. Computed Tomography (CT) and Magnetic Resonance Imaging (MRI) scans revealed a large, lobulated, complex mass occupying the lower abdomen and pelvis with extension to the left ischiorectal fossa. An aggressive angiomyxoma (AAM) was considered as one of the differentials for this mass. Multiple attempts at radiological guided biopsy were performed, but with non-diagnostic yield. Intraoperatively, the mass encased the sigmoid colon, rectum, vaginal wall, and was adherent to bilateral pelvic sidewalls, pelvic floor, and left ischiorectal fossa. Enbloc resection of the mass, including an abdominoperineal resection and a total abdominal hysterectomy bilateral salpingo-oophrectomy (TAHBSO) was performed. Final histology showed features consistent with myxoid leiomyoma (ML).

Conclusion: The radiological and pathological resemblance of ML and AAM presents a great diagnostic challenge. However, the actual diagnosis lies in the pathological analysis. Surgical resection with clear margins is the treatment of choice in the absence of a definite diagnosis. Prognosis of these tumours is generally good with low recurrence rates.

\section{Key words}

Myxoid leiomyoma, Extrauterine, Aggressive angiomyxoma

\section{I ntroduction}

Myxoid leiomyoma (ML) is defined as benign smooth muscle tumour that consists of monomorphic spindle cells arranged in interweaving fascicles with prominent myxoid appearance ${ }^{[1]}$. Aggressive angiomyxoma (AAM) on the other hand, is a rare, infiltrative, slow-growing benign mesenchymal neoplasm with loose myxoid stroma containing cytologically bland stellate or spindled cells ${ }^{[2]}$. Differentiating between ML and AAM has always been a challenge. In view of their similarities both clinically and radiologically, the actual diagnosis lies mainly in the pathological analysis. A rare case of an extrauterine ML in a 47-year-old woman is described here. The purpose of this article is to highlight the diagnostic challenges and to discuss the radiological and pathological aspects of these tumours. 


\section{Case report}

A 47-year-old woman was referred to us for a mass that was incidentally found during routine health examination in the United Arab Emirates. She complained of increase in abdominal girth which she attributed to weight gain. Her gynaecological history included two previous caesarean sections and her previous medical history was not significant. On examination, she had a large pelvic mass extending up to the xiphoid process. Gynaecological and systemic examinations were otherwise normal. Tumour markers (CEA, CA 19-9) were all normal except for a raised serum CA 125 level of 78.8. Computed Tomography (CT) scan of the abdomen and pelvis from the United Arab Emirates reported a large pelvic mass, and a trans- ischiorectal biopsy which was performed at that time reported spindle cells. She was then referred to a gynaecologic oncologist in Singapore for further evaluation. Pap smear and endometrial biopsy were both negative for malignancy.

A Fluorodeoxyglucose/Positron Emission Tomography (FDG/PET) study from the vertex of the skull to the upper thighs was performed that revealed a large, lobulated, complex mass occupying the lower abdomen and pelvis measuring up to 21 $\mathrm{cm} \times 14 \mathrm{~cm} \times 11 \mathrm{~cm}$ with extension to the left ischiorectal fossa. It engulfed the uterus and rectosigmoid colon which retained near normal configurations as they were not significantly compressed by the surrounding large mass (see Figure 1). Functionally, the mass exhibited relatively low FDG uptake with a maximum Standardized Uptake Value (SUV) of 3.6. No other suspicious hypermetabolic focus was found. Resonance Imaging (MRI) pelvis was then performed which demonstrated a heterogeneously enhancing mass in the lower abdomen and pelvis (see Figure 2). It closely apposed bilateral pelvic side walls and the pre-sacral space. Encasement of the uterus, sigmoid and rectum were noted again without significant local mass effect. The mass extended inferiorly through the left levator ani muscle into the left ischiorectal fossa and left perineum. It exhibited a laminated or swirled appearance, best seen on the coronal sequence (see Figure 3).
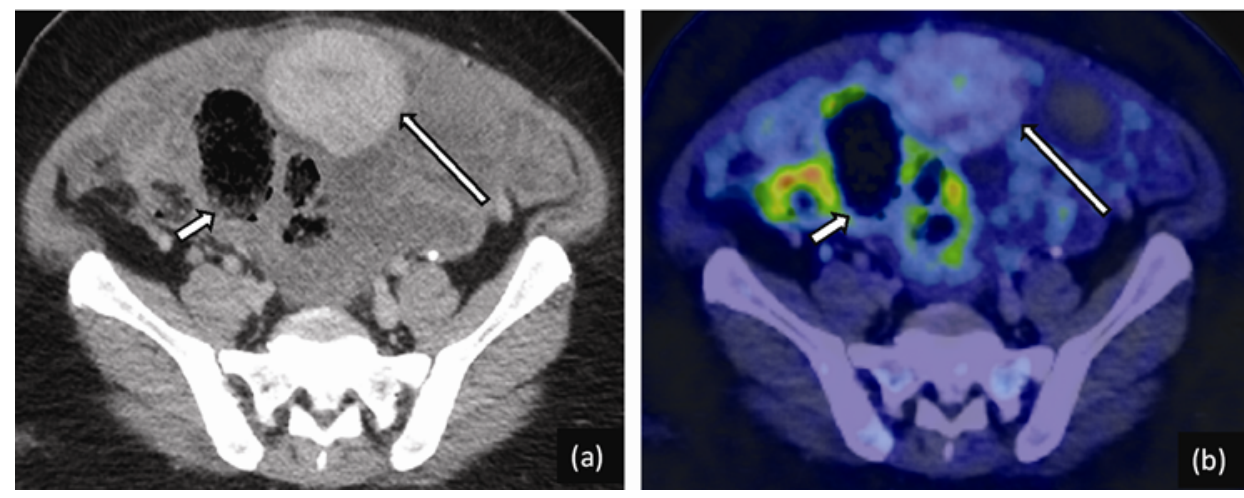

Figure 1. A large lobulated mass engulfing the uterus (long arrow) and sigmoid colon (short arrow). The uterus and bowel however, retain a near normal configuration without significant mass-effect by the surrounding mass. Functionally, the mass demonstrates relatively low FDG uptake with a SUVmax of 3.6.

Colonoscopy was performed and revealed sigmoid diverticular disease. CT-guided percutaneous needle biopsy of the mass through the perineum was carried out without conclusive findings. A repeat transabdominal ultrasound-guided needle biopsy showed small fragments of fibroconnective tissue with bland spindle cells which were disposed within loose collagenous stroma. There were no mitosis or cytologic atypia identified. In view of increased abdominal distension with multiple inconclusive histopathological findings from biopsies that could not rule out the diagnosis of malignancy, a thorough discussion with the patient was conducted and the decision was made for resection of the mass.

During laparotomy, the large abdomino-pelvic mass was encasing the sigmoid colon, rectum, vaginal wall, and was adherent to bilateral pelvic sidewalls, pelvic floor, and left ischiorectal fossa. In view of the mass being adherent to the pelvic floor and extending closely towards the anal verge, an abdomino-perineal resection with end colostomy, as well as total abdominal hysterectomy bilateral salpingo-oophrectomy (TAHBSO), was performed with the en-bloc tumour 
resection (see Figure 4). Peritoneal fluid was negative for malignancy. Intraoperative frozen section showed fibrocollagenous tissue with bland spindle cells. The aorta and vena cava, as well as liver, kidneys and spleen were not affected by the mass. There was no ascites nor peritoneal disease seen.

Figure 2. The large mass demonstrates heterogeneous enhancement on fat-saturated post-contrast enhanced sequence. The mass encompasses the uterus (long arrow) and rectum (short arrow) without significant mass-effect.

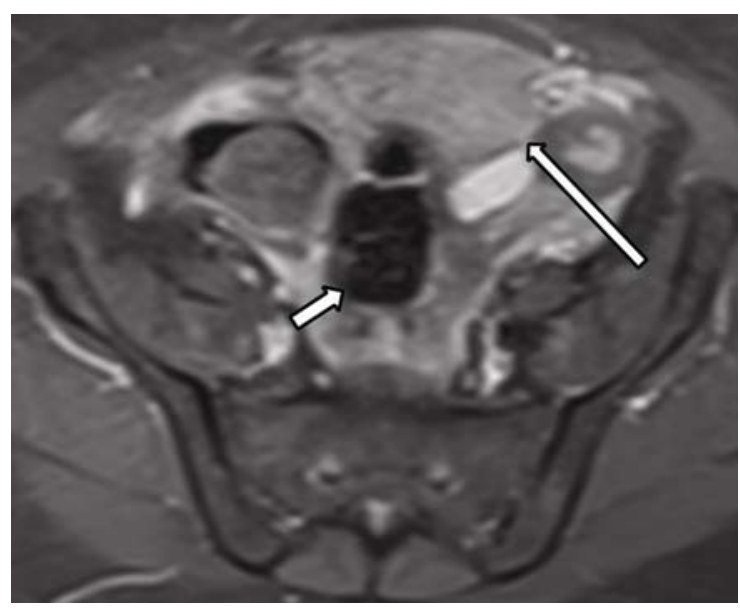

Figure 3. Coronal image shows extension of the mass inferiorly through the left levator ani muscle into the left ischiorectal fossa. It demonstrates a laminated or swirled appearance typically described in aggressive angiomyxomas.
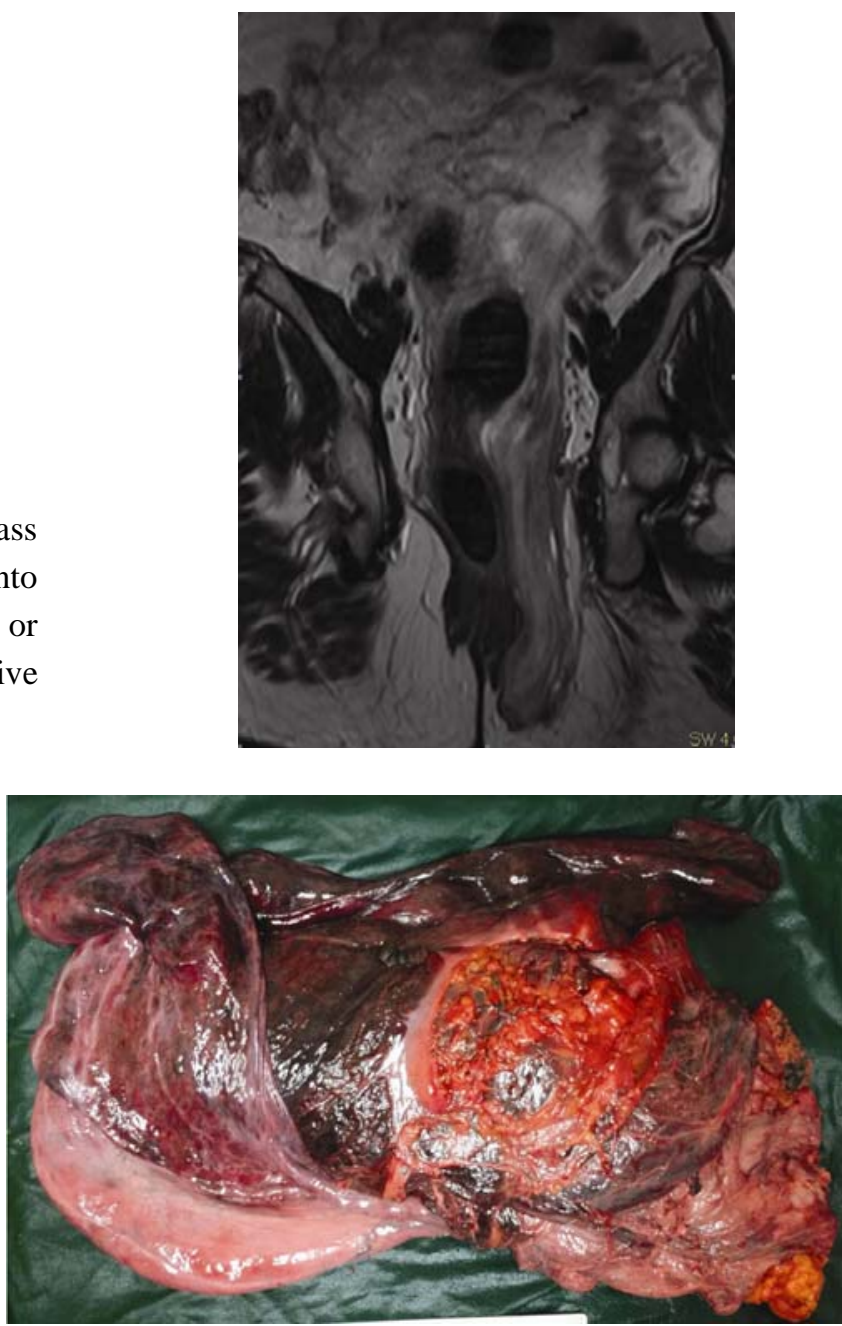

Figure 4. Gross appearance of the tumour.

After resection of the mass, the abdomen was closed in layers. The resected tumour weighed $8 \mathrm{~kg}$ and measured $47 \mathrm{~cm} \times 45$ $\mathrm{cm} \times 9 \mathrm{~cm}$ in size. Gross examination showed a myxoid cut surface with scattered tan solid areas at least $15 \mathrm{~mm}$ in size. Final histology reported features consistent with myxoid leiomyoma with estrogen receptor (ER) and progesterone Published by Sciedu Press 
receptor (PR) positivity. The spindled tumour cells immunostain positively for smooth muscle actin, desmin and high molecular weight caldesmon (see Figure 5). This is the immunoprofile of cells showing smooth muscle differentiation. Immunistaining for beta-catenin, C-KIT, DOG1, CD34, CD10, Melan-A, HMB45, and keratin were negative. The myxoid foci merged into cellular fascicular areas with spindled tumour cells containing eosinophilic cytoplasm consistent with smooth muscle differentiation. There were no nuclear atypia, mitotic activity or tumour necrosis seen (see Figures 6 and 7). Post-operatively, the patient recovered uneventfully and was discharged well.

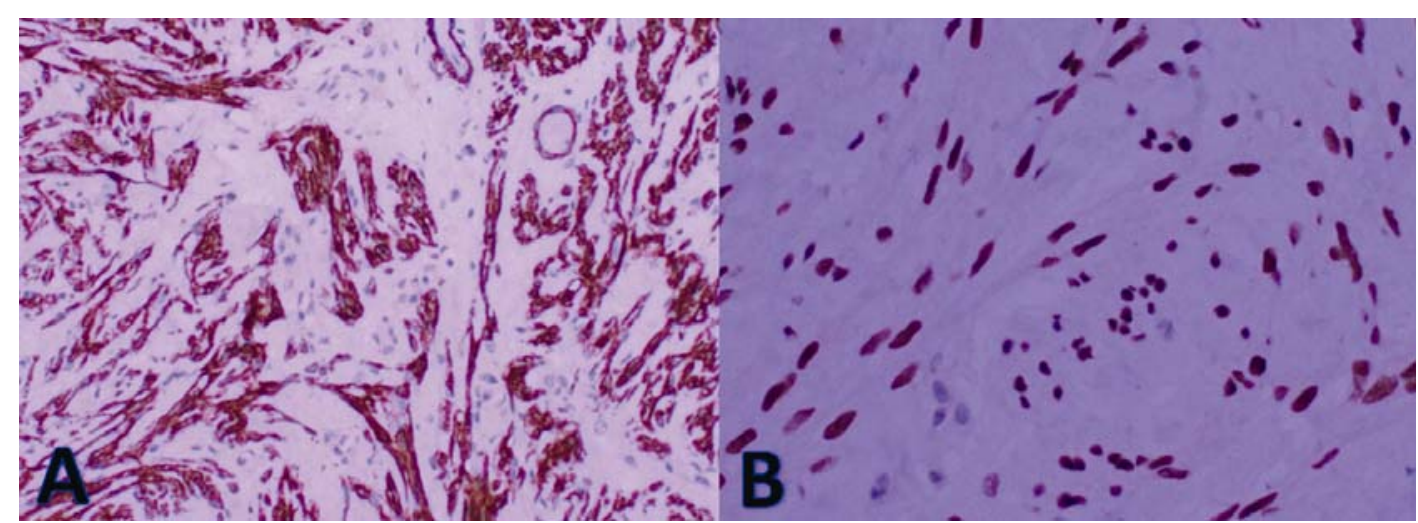

Figure 5. (A) Positive cytoplasmic immunostaining with Caldesmon (200×). (B) Positive nuclear immunostaining with estrogen receptor $(200 \times)$.

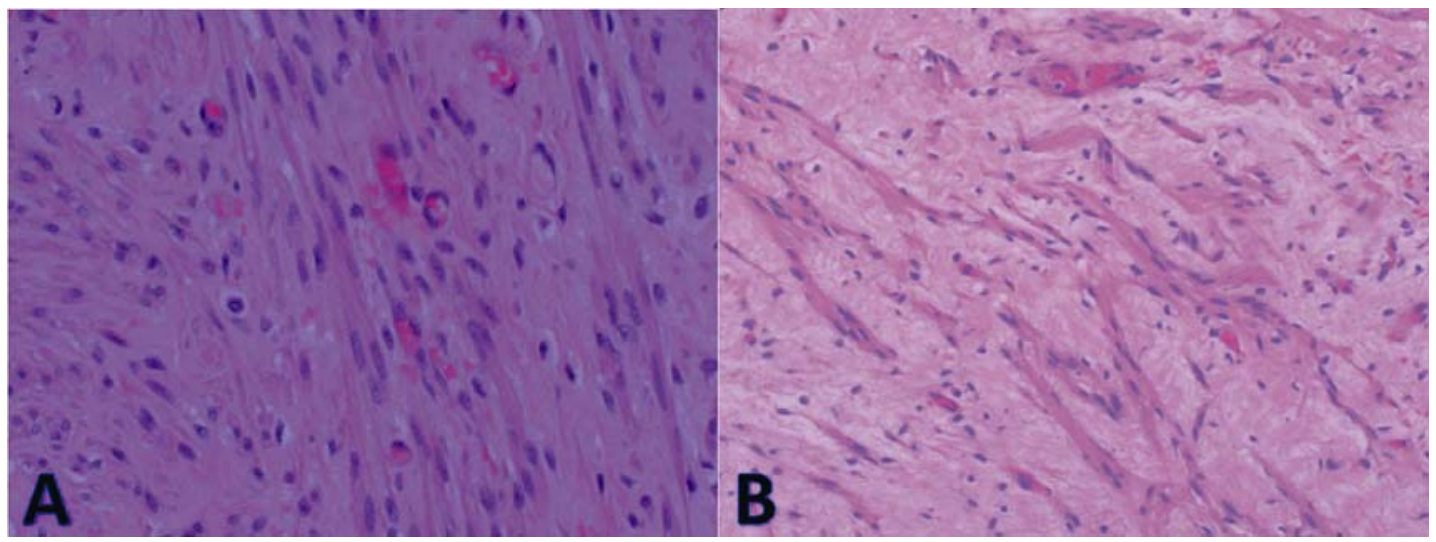

Figure 6. (A) Solid cellular areas showing spindle cells with smooth muscle differentiation and no atypia (200×). (B) Bland smooth muscle cells in a myxoid stroma (200×).

Figure 7. Black arrows showing non-specific ovoid cells in my myxoid stroma (200×)

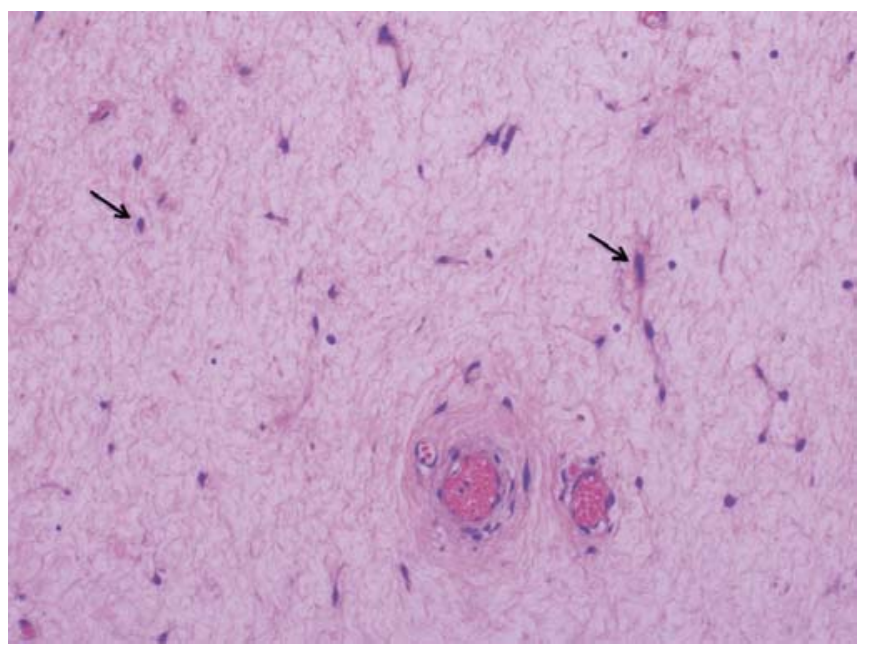




\section{Discussion}

Uterine leiomyoma is the most common gynaecologic neoplasm affecting $35 \%$ to $70 \%$ of all women during their reproductive life ${ }^{[3]}$. They are histologically benign tumours that originate from smooth muscle cells. Extrauterine leiomyomas are very rare and present a greater diagnostic challenge ${ }^{[4]}$. Radiologically, leiomyomas typically demonstrate low-signal intensity on T1-weighted and T2-weighted imaging, although those which demonstrate myxoid features show high signal intensity on T2-weighted sequence, as in our case. There are, however, leiomyomas that grow in unusual patterns and locations, making the diagnosis more challenging. There have been case reports reporting extrauterine leiomyomas arising from the gastrointestinal tract, genitourinary tract, as well as other rare locations including sinonasal cavities, orbits, and skin ${ }^{[5-13]}$. Abnormal growth patterns including retroperitoneal and parasitic growth have also been described, and tend to occur in women with a history of hysterectomy or surgery for uterine leiomyomas ${ }^{[4,14]}$. Histologically, ML consists of monomorphic spindle cells arranged in interweaving fascicles with prominent myxoid appearance. The smooth muscle cells are elongated with eosinophilic cytoplasm and uniform, cigar-shaped nuclei. Mitotic index for ML is usually less than 2 per 10 high power field with no cytological atypia or necrosis. ER and PR are invariably positive in these tumours ${ }^{[1]}$.

AAM is a rare, infiltrative, slow-growing benign mesenchymal neoplasm that is more common in females of reproductive age, with a peak incidence in the fourth to fifth decades of life ${ }^{[15]}$. It is commonly located in the pelvis and perineum with the mass on either side of the pelvic diaphragm ${ }^{[16]}$. AAM shares very similar radiological characteristics with ML. It demonstrates high T2-weighted signal intensity secondary to a myxoid matrix with a classically described laminated or swirled appearance as suggested in our case ${ }^{[16,17]}$. AAM also shows low FDG avidity ${ }^{[16]}$. It is termed aggressive due its locally infiltrative nature and tendency to recur following resection ${ }^{[18]}$. These tumours are highly vascularised histologically with loose myxoid stroma containing cytologically bland stellate or spindled cells. They are characteristically ER and PR positive as well ${ }^{[2]}$. However, it has a low metastatic capacity with an overall favourable prognosis and surgical resection is the mainstay of treatment ${ }^{[19]}$.

In this case, it was difficult to identify the origin of this tumour both radiologically and pathologically, and the aggressive infiltrative features that the mass exhibited were not typical of ML. In addition, multiple inconclusive findings on tissue biopsy with non-characteristic radiological findings led us to suspect a malignant origin. Complete surgical resection with clear margins is the mainstay treatment for these tumours. Although most case series show good prognosis with no recurrence in extrauterine leiomyomas, there is a small potential for recurrence in patients with positive resection margins ${ }^{[5,6,20,21]}$. Regrowth of extrauterine leiomyomas has been documented in up to $30 \%$ of patients ${ }^{[4]}$. In AAM, the documented rate of local recurrence due to failure of obtaining adequate clear margins after primary resection is more than $35 \%{ }^{[16]}$.

Histological resemblance between ML and AAM has been described ${ }^{[22]}$. Both tumours contain spindle cells and vascular structures distributed in a myxoid background. According to Nemoto, the presence of interlacing smooth muscle bundles may be a diagnostic clue, but not pathognomonic of $\mathrm{ML}^{[22]}$. ML also contains a more abundant eosinophilic cytoplasm with more focal myxoid change compared to AAM. Sutton stated that it is helpful microscopically to identify areas of transition between myxoid features and a classical smooth muscle differentiation in order to determine its morphological pattern ${ }^{[2]}$. Serious consideration was given to the diagnosis of AAM. However, there were clearly defined solid areas on gross examination that, on microscopy, show elongated spindled nuclei with eosinophilic cytoplasm. The impression of smooth muscle differentiation was confirmed by positive immunostaining for smooth muscle actin, desmin and high molecular weight caldesmon. These areas merged with myxoid areas containing morphologically and immunehistochemically similar cells. These solid foci cannot be attributed to any normal anatomic structure in the abdomen.

In conclusion, obtaining an accurate diagnosis of extrauterine ML remains a challenge. The actual diagnosis lies in the pathological analysis. It is important to obtain clear resection margins to prevent tumour regrowth and recurrence. Prognosis and outcomes of these tumours are generally good. 


\section{Conflict of interest and funding}

The authors declare that they have no conflict of interest and have not received any funding or benefits from industry to write this article.

\section{References}

[1] Al- Nafusi A. Uterine smooth-muscle tumours: Practical approach to diagnosis. Curr Diagm Pathol. 2004; 10(2): $140-56$. http://dx.doi.org/10.1016/S0968-6053(03)00072-3

[2] Sutton BJ, Laudadio J. Aggressive angiomyxoma. Arch Pathol Lab Med. 2012 Feb; 136(2): 217-21. http://dx.doi.org/10.5858/arpa.2011-0056-RS

[3] Markowski DN, Helmke BM, Bartnitzke S, et al. Uterine Fibroids: Do we deal with more than one disease? Int J Gynaecol Pathol. 2014 Oct l; 33: 568-572.

[4] Mahmoud MS, Desai K, Nezhat FR. Leiomyomas beyond the uterus; benign metastasizing leiomyomatosis with paraaortic metastasizing endometriosis and intravenous leiomyomatosis: a case series and review of the literature. Arch Gynecol Obstet. 2014 Jul 22. PMid: 25047270. http://dx.doi.org/10.1007/s00404-014-3356-8

[5] Hatch KF, Blanchard K, Hatch G III, Wertheimer-Hatch L, Davis G, Foster R, et al. Tumors of the appendix and colon. World J Surg. 2000; 24: 430-6. PMid: 10706915. http://dx.doi.org/10.1007/s002689910068

[6] Sayer RA, Amundsen CL. Giant pelvic retroperitoneal leiomyoma arising from the rectal wall. Obstet \& Gynaecol. May 2003; 101(5 Pt 2): 1132-4. http://dx.doi.org/10.1016/S0029-7844(03)00066-8

[7] Reyad MM, Gazvani MR, Khine MM. A rare case of primary leiomyoma of the vulva. J Obstet Gynaecol. 2006 Jan; $26(1)$ : 73-74. PMid: 16390721. http://dx.doi.org/10.1080/01443610500419451

[8] Fallahzadeh H, Dockerty MB, Lee RA. Leiomyoma of the ovary: report of five cases and review of the literature. Am J Obstet Gynecol. 1972 Jun 1; 113(3): 394-398. PMid:4118003

[9] Saad AG, Kaouk JH, Kaspar HG, et al. Leiomyoma of the urethra: report of 3 cases of a rare entity. Int J Surg Pathol. 2003 Apr; 11(2): 123-126. PMid: 12754634. http://dx.doi.org/10.1177/106689690301100213

[10] Goluboff ET, O’Toole K, Sawczuk IS. Leiomyoma of bladder: report of case and review of literature. Urology. 1994; 43(2): 238-241. http://dx.doi.org/10.1016/0090-4295(94)90053-1

[11] Tseng PY, Lai YS, Chen MK, et al. Progesterone receptor expression in sinonasal leiomyoma: A case report and review of literature. Int J Clin Exp Pathol. 2014 Feb 15; 7(3): 1224-8. PMid: 24696741.

[12] Remmer MH, Kaliki S, Eagle RC, et al. Giant Leiomyoma of the ciliary body. Oman J Opthalmol. 2014 May; 7(2): 81-3. http://dx.doi.org/10.4103/0974-620X.137165

[13] Dilek N, Yuksel D, Sehitoglu I, et al. Cutaneous leiomyoma in a child: A case report. Oncol Lett. 2013 Apr; 5(4): $1163-1164$. PMid: 23599756

[14] Al Manasra AR, Malkawi AS, Khammash MR. Parasitic leiomyoma. A rare cause of inguinal mass in females. Saudi Med J. 2011 Jun; 32(6): 633-5. PMid: 21666948.

[15] Goyal P, Agrawal D, Sehgal S, Ghosh S, Kumar A, Singh S. Aggressive angiomyxoma in pregnancy. Rare Tumors. 2014 Jun 4; 6(2): 5362. http://dx.doi.org/10.4081/rt.2014.5362

[16] Surabhi VR, Garg N, Frumovitz M, Bhosale P, Prasad SR, Meis JM. Aggressive angiomyxomas: a comprehensive imaging review with clinical and histopathologic correlation. AJR Am J Roentgenol. 2014 Jun; 202(6): 1171-8. http://dx.doi.org/10.2214/AJR.13.11668

[17] Petscavage-Thomas JM, Walker EA, Logie CI, Clarke LE, Duryea DM, Murphey MD. Soft-tissue myxomatous lesions: review of salient imaging features with pathologic comparison. Radiographics. 2014 Jul-Aug; 34(4): 964-80. http://dx.doi.org/10.1148/rg.344130110

[18] Kiran G, Yancar S, Sayar H, Kiran H, Coskun A, Arikan DC. Late recurrence of aggressive angiomyxoma of the vulva. J Low Genit Tract Dis. 2013 Jan; 17(1): 85-7. http://dx.doi.org/10.1097/LGT.0b013e3182545d2f

[19] Narang S, Kohli S, Kumar V, Chandoke R. Aggressive angiomyxoma with perineal herniation. J Clin Imaging Sci. 2014 Apr 30; 4: 23. http://dx.doi.org/10.4103/2156-7514.131740

[20] Chen CW, Jao SW, Wu CC, et al. Massive lower gastrointestinal haemorrhage caused by a large extraluminal leiomyoma of the colon: Report of a case. Dis Colon Rectum. 2008 Jun; 51(6): 975-978. http://dx.doi.org/10.1007/s10350-007-9190-3

[21] Billings SD, Folpe AL, Weiss SW. Do leiomyomas of deep soft tissue exist? An analysis of highly differentiated smooth muscle tumors of deep soft tissue supporting two distinct subtypes. Am J Surg Pathol. 2001 Sep; 25(9): 1134-1142. PMid: 11688572. http://dx.doi.org/10.1097/00000478-200109000-00003

[22] Nemoto T, Shinoda M, Komatsuzaki, et al. Myxoid leiomyoma of the vulva mimicking aggressive angiomyxoma. Pathol Int. 1994 Jun; 44(6): 454-459. PMid: 8055112. http://dx.doi.org/10.1111/j.1440-1827.1994.tb01710.x 